\title{
A population-based study of testicular cancer risk among children and young adults from Norway and Utah, USA
}

Ruby Del Risco Kollerud ${ }^{\mathrm{a}, b^{*}}$, Hege S. Haugnes ${ }^{\mathrm{c}, \mathrm{d}}$, Bjørgulf Claussen ${ }^{\mathrm{a}}$, Magne Thoresen ${ }^{\mathrm{e}}$, Per Nafstad $^{\mathrm{a}}$, James M Farnham ${ }^{\mathrm{f}}$, Karl Gerhard Blaasaas' ${ }^{\mathrm{g}}$, Øyvind Næss ${ }^{\mathrm{a}}$, Lisa A. CannonAlbright ${ }^{f}$.

anstitute of Health and Society, University of Oslo, P.O Box 1130 Blindervn, 0318 Oslo, Norway

bThe National Centre for Occupational Rehabilitation in Norway. Haddlandsvegen 20, 3864 Rauland, Norway

'Department of Oncology, University Hospital of North Norway, Tromsø ${ }^{\mathrm{d} I n s t i t u t e}$ of Clinical Medicine, UIT- The Arctic University, Tromsø, Norway eDepartment of Biostatistics, Oslo Centre for Biostatistics and Epidemiology, University of Oslo, Norway.

${ }^{\mathrm{f}}$ Genetic Epidemiology, Department of Internal Medicine, University of Utah School of Medicine, Salt Lake City, UT, 84108 USA.

gFinance Norway, P.O Box 2473 Solli, 0202, Oslo Norway

* Corresponding author. Tel.: +4747970236; fax: +4735073268

E-mail address: ruby.kollerud@hotmail.com

Novelty and Impact

A clear difference in testicular cancer incidence among individuals born in Norway and descendants of Scandinavian people born in Utah was observed. Norwegian males born between 1980 and 1984 had twice the testicular cancer incidence found in Utah in the same period.

These differences in testicular cancer rates point to the possibility of environmental influences and/or lifestyle factors.

Family history of testicular cancer is a strong risk factor for developing testicular cancer in both populations.

\section{Abbreviations}

TC: testicular cancer

UPDB: Utah Population Database

DSF: the Norwegian National Population Register

UCR: the Utah Cancer Registry

NCI: National Cancer Institute

SEER: the Surveillance, Epidemiology, and End Results

ICDO-3: International Classification of Diseases for Oncology

HR: hazard ratios 


\begin{abstract}
Similar family-based cancer and genealogy data from Norway and Utah allowed comparisons of the incidence of testicular cancer (TC), and exploration of the role of Scandinavian ancestry and family history of TC in TC risk.

This study utilizes data from the Utah Population Database and Norwegian Population Registers. All males born during 1951-2015 were followed for TC until the age of 29 years. A total of 1,974,287 and 832,836 males were born in Norway and Utah, respectively, of whom 2,686 individuals were diagnosed with TC in Norway and 531 in Utah. The incidence per year of TC in Norway (10.6) was twice that observed in Utah (5.1) for males born in the last period (1980-1984). The incidence rates of TC in Utah did not differ according to presence or absence of Scandinavian ancestry $(\mathrm{p}=0.669)$. Having a brother diagnosed with TC was a strong risk factor for TC among children born in Norway and Utah, with HR=9.87 (95\% CI 5.68-17.16) and 6.02 (95\% CI 4.80-7.55), respectively; with even higher HR observed among the subset of children in Utah with Scandinavian ancestry (HR=12.30 95\% CI 6.78- 22.31).
\end{abstract}

A clear difference in TC incidence among individuals born in Norway and descendants of Scandinavian people born in Utah was observed. These differences in TC rates point to the possibility of environmental influence. Family history of TC is a strong risk factor for developing TC in both populations.

\title{
Keywords
}

Testicular cancer, testis, testicular cancer incidence, germ cell tumour, familial aggregation, family history, familial risk, UPDB, children. 


\section{Introduction}

Germ-cell testicular cancer (TC) is the most frequent solid cancer among young Caucasian males. ${ }^{1}$ For unknown reasons, the incidence of TC has increased substantially in many countries during the last five decades, with the highest incidence found in Denmark and Norway. ${ }^{2,3}$ In several countries, incidence trends of TC are consistent with birth-cohort effects, suggesting that any risk factor associated with increased incidence would vary with birth cohorts. ${ }^{4}$ A cohort effect occurs when different distributions of disease arise from a changing or new environmental cause affecting age groups differently. ${ }^{5}$

The aetiology of TC remains largely unknown. A family history of TC and other cancers is a strong risk factor for TC. ${ }^{6}$ A recent study found evidence for a moderate penetrance TC susceptibility gene. However, specific high-penetrance susceptibility genes predisposing to TC have not been identified. ${ }^{7,8}$ Moreover, recent studies show that genetic susceptibility for the risk of TC is mediated by more than 50 susceptibility loci, each providing a low or moderate risk. ${ }^{9},{ }^{10}$

The risk factor most consistently associated with TC is cryptorchidism, which together with additional disorders of the male reproductive system including hypospadias and impaired spermatogenesis have been grouped into the Testicular Dysgenesis Syndrome. ${ }^{11}$ Considering that TC peaks in incidence among young men of reproductive age it is believed that high oestrogen levels in utero may contribute to the development of TC (the oestrogen hypothesis, Sharpe and Skakkebaek, 1993). ${ }^{12}$ The so-called oestrogen hypothesis has been expanded to include also environmental antiandrogens as endocrine disrupters with potential adverse effect on male reproductive health. ${ }^{13}$ However, relatively few chemicals have so far been closely examined for their possible hormone activity in humans.

In the latter half of the 19th century and the first decades of the 20th century, over one million Scandinavians emigrated to America; some were members of the Latter-Day Saints church from the Mormon Scandinavian Mission. 14,15,16,17 They had many of the same motives as other migrants, but in addition they were directly encouraged to settle in Utah where most of the population still practices the Mormon religion. This population is well-known for their lifestyle characteristics including large family size, a healthy lifestyle, and proscriptions against alcoholic beverages and tobacco. ${ }^{18}$ Children born in Utah with Scandinavian ancestry 
will share genes with people from Scandinavian countries, but they have grown up in different environments. The increase and high incidence of TC in Norway may be caused by genetic and/or environmental factors. For the purpose of investigating the roles of genetic and environmental factors we used triangulation, integrating two different methods to analyse data. ${ }^{19}$ We investigated TC cancer incidence in children born in Utah with Scandinavian ancestors as a means to evaluate the impact of the Utah environment on cancer risk and the potential timing of an environmental factor. In addition, we also explored family history of cancer as indicator for a possible environmental and/or genetic influence. Using data from the Utah Population Database (UPDB) and the Norwegian National Population Register (DSF), we were able to conduct a unique comparison of incidence and family history of cancer in Utah and in Norway. The aim of this study was to

1) explore and compare TC incidence in males $<30$ years born in Norway and Utah, taking Scandinavian ancestry into account

2) explore trends of TC incidence over time

3) evaluate the risk of developing TC with regard to family history of TC.

\section{Materials and methods}

\subsection{Study population}

All males born during 1951-2015 in Norway and Utah who were also registered in UPDB or DSF were included in the study. The UPDB is one of the world's richest sources of linked population-based information and contains data for over 9 million individuals and their descendants from the late 18th century to the present. It was originally constructed based on data provided by the Genealogical Society of Utah and is kept current with state vital statistics data. ${ }^{20}$ The Norwegian DSF has information on the relationship between each individual person and his/her relatives. Every person in the register has a Norwegian personal identification number which makes it possible to link the person with other registries. These databases enable us to follow all individuals from birth to death, end of study or emigration. Regarding emigration from Utah we used the last known date of residence, which is determined by when the individual had an event recorded in Utah from vital records (deaths, births, adoptions, marriages, divorces, Utah driver's license registration and renewal, voter registration, census data and state-wide inpatient and ambulatory care).

\subsection{Cancer cases}


Cancer cases among all included males and their relatives were identified through linkage of the two databases to cancer registries, the Utah Cancer Registry (UCR), an NCI Surveillance, Epidemiology, and End-Results (SEER) Registry from 1973, which includes all independent primary cancer diagnoses for Utah residents from 1966 through 2015, and the Norwegian Cancer Registry, which was initiated in 1953. ${ }^{21,22}$ By law, all incident cancer diagnoses must be reported to both registries.

Cases or index persons were all males diagnosed with TC before the age of 30 between 1953 and 2015 in Norway and between 1966 and 2015 in Utah. TC was classified into seminomas and non-seminomas using the International Classification of Diseases for Oncology (ICDO-3) and topography (C62). (Appendix 1). Family history of TC was classified according to the ICD-10 (Appendix 1).

\subsection{Scandinavian ancestry}

In the UPDB we defined ancestry as an individual's ethnic origin, or place of birth of an individual's ancestors prior to arrival in Utah. To compare ancestry groups, we split the population in Utah into children with Scandinavian ancestry and children with nonScandinavian ancestry. Appendix 2 describes the method used for the identification of Scandinavian ancestry.

\subsection{Statistical analysis}

Incidence rates of TC with 95\% confidence intervals (CI) for seven 5-year birth cohorts were calculated for individuals born between 1951 and1984, to allow the same time frame (until the age of 30) for each individual to develop TC. The rates were calculated by dividing the total number of TC cases in each cohort by the total number of follow-up years multiplied by 100,000. A Poisson model was used to evaluate whether TC incidence had changed over time.

We present TC incidence rates for the population aged 0-29 years in Norway and Utah, and according to Scandinavian ancestry.

To analyse the impact of family history of TC on risk of TC, we used stratified Cox regression, where each birth cohort (10-year time period) was entered as a separate stratum. Using this approach, we could control for secular trends in the disease and birth-cohort effects reported in other studies. The person-time at risk was defined in both Utah and in Norway 
from birth to the age of a diagnosis, with censoring at the age of 30 years, death, emigration, end of study or the last known date of residence in Utah.

We present hazard ratios (HR) and 95\% CI for the risk of TC among index persons in association with TC in the first-degree relatives separately for fathers, brothers, and all firstdegree relatives. The results are presented for the whole population in Utah and in Norway. Analyses were adjusted for number of known male relatives. In addition, we conducted several comparisons between ancestry groups. The comparisons are corrected for multiple testing by the Bonferroni correction (Appendix 1).

The proportional hazards assumption was verified by plotting Schoenfeld residuals. All analyses were performed using SPSS version 25.

Ethics approval and consent to participate: This study was approved by the Institutional Review Boards of the University of Utah and by the Utah Resource for Genetic and Epidemiologic Research (IRB_00090583). In Norway the project was approved by the Regional Committees for Medical and Health Research Ethics, (REK Sør-Øst: 2016/1305). As this is a register-linked study, the approval also covers exemption from informed consent because that would not be feasible to acquire.

Data availability. Data can be made available upon approval from the Institutional Review Boards of the University of Utah, the Utah Resource for Genetic and Epidemiologic Research and the Regional Committees for Medical and Health Research Ethics in Norway.

\section{Results}

During the 64-year study period, a total of 1,974,287 and 832,836 male births were recorded in Norway and the Utah data resource, respectively (Table 1). Overall $68 \%$ of these Utah children had ancestral roots from Scandinavia, of which $20.2 \%$ had ancestral roots from Norway specifically. Appendix 2 shows a distribution of ancestry values for children and young adults with ancestry from Scandinavia. During the follow-up period, 2,686 index persons were diagnosed with TC in Norway and 531 in Utah.

\subsection{TC incidence}


We observed a tendency towards an increase in TC incidence with consecutive birth cohorts in both countries (Figure 1), with the highest incidence rates observed among the most recent birth cohorts analysed in Norway. This trend was statistically significant in both Norway ( $\mathrm{p}<$ $0.001)$ and in the whole population of Utah $(p<0.001)$. In Norway, incidence rates were ranging from 2.6 among individuals born during 1951-1954 to 10.6 among individuals born during 1980-1984. In the Utah data, the rates were lower, ranging from 2.3 for individuals born during 1951-1954 to 5.1 among individuals born during 1980-1984. Incidence rates of TC among individuals born in the last periods of the study in Utah and Norway showed less increase in incidence compared with earlier cohorts. There was no CI overlap from 1960 and later, indicating that these differences in TC incidence between Norway and Utah were statistically significant after that period.

Individuals with Scandinavian ancestors in Utah also showed a similar trend for increasing incidence of TC $(p=0.003)$, while it was not significant for the non-Scandinavian Utah population $(\mathrm{p}=0.06)$. However, looking at the plot (Figure 1$)$, the trends are very similar and indeed, the incidence rates of TC in Utah did not differ significantly according to presence or absence of Scandinavian ancestry $(p=0.66)$.

Non-seminoma TC tumours showed the highest incidence rates in both countries, and statistically significant increasing trends with consecutive birth cohorts, in both Norway $(\mathrm{p}<$ $0.001)$ and Utah $(\mathrm{p}=0.003)$ (Figure 2). Seminomas showed lower incidence rates than nonseminomas, with a statistically significant increased incidence in Norway $(p<0.001)$, but not in $\operatorname{Utah}(\mathrm{p}=0.085)$.

\subsection{Family history of TC and TC risk}

Overall, we observed an association between a family history of TC in first-degree relatives and risk of TC in index persons in both Norway and Utah (Table 2). Having a brother diagnosed with TC was the strongest risk factor for TC among children born in both Utah (9.9-fold) and in Norway (6-fold). When the Utah results were stratified by Scandinavian ancestry (data not shown) we observed a higher risk for TC when a brother was diagnosed with TC among individuals with Scandinavian ancestry (12.3-fold) than among individuals without Scandinavian ancestry (5.9-fold). However, these two hazard ratios were not significantly different from each other $(\mathrm{p}=0.14)$. 


\section{Discussion}

To our knowledge, this is the first population-based study to examine differences in incidence and family risk of TC in individuals born in USA with Scandinavian ancestry. We found a significant increase in incidence of TC with increasing year of birth in both populations, but more pronounced in Norway than in Utah. Norwegian males born between 1980 and 1984 had twice the TC incidence found in Utah in the same period.

Our results are concordant with earlier publications of adult TC incidence in Europe, $23,24,25$ Canada, ${ }^{26}$ and the USA. ${ }^{27,28}$ In Denmark men born around 1943 and 1968 showed lower incidence rates than men born just before or just after these years. ${ }^{30}$ The authors of the Danish study attributed these lower rates to a rapid change in risk factors for TC among these cohorts. We found that the uninterrupted increase in TC incidence observed in Norway from 1951 to 1979 flattened out for young men born in the subsequent period (1980-1984), probably also explained by change in TC risk factors, yet to be discovered.

Lower incidence rates of TC in Utah than in Norway may be explained by differences in risk factors between the two populations. Epidemiological studies suggest that the incidence of both cryptorchidism and hypospadias has increased in many countries. However, the authors emphasize that registry-based studies do not permit reliable comparisons due to possible under-reporting, ${ }^{29}$ making comparison between Utah and Norway difficult. An underlying mechanism of the Testicular Dysgenesis Syndrome could be a shared heritability of these conditions, but there is evidence that a family history of hypospadias or cryptorchidism is not associated with a general increase in the risk of developing TC. ${ }^{30}$

In 1993, Sharpe and Skakkebaek proposed the "oestrogen hypothesis" which postulated that the increase in male reproductive developmental disorders might have occurred because of increased oestrogen exposure of the human foetus or neonate. ${ }^{31}$ This hypothesis has been revised in 2001 by introducing the concept of Testicular Dysgenesis Syndrome, a male reproduction-related condition characterized by the presence of symptoms and disorders such as TC, undescended testes, hypospadias and poor semen quality. The rapid increase in the incidence of these disorders in recent years indicates that the causes might be due to environment factors. ${ }^{32,33}$ Systematic reviews examining the association between TC and exposure to estrogenic agents in utero include relatively few studies, small study samples and 
high study heterogeneity, making it difficult to have conclusive evidence for such association. $^{34}$

Diet might influence circulating hormone levels, by affecting steroid hormone status. ${ }^{35}$ Lifestyle factors related to pregnancy, such as maternal smoking and alcohol consumption have also been linked to the risk of TC. Both cryptorchidism and low birth weight have been associated with the risk of TC and maternal smoking. However, more recent studies do not support this hypothesis. ${ }^{36}$ Alcohol consumption is associated with lower maternal testosterone levels in pregnancy, and this in turn is associated with higher risk of TC. ${ }^{37}$ Some of these risk factors may differ between Utah and Norway.

Mormons have a health code that promotes healthy behaviours such as eating fruits, vegetables and grains and limiting meat, and excludes alcoholic beverages, tobacco, coffee, tea, and other addictive substances. For instance, Utah has the smallest proportion of smokers of any U.S. state (8.9\%), while the current smoking prevalence in Norway is $12 \%{ }^{38,39}$ Mormon women are more likely to have more pregnancies and less likely to use birth control pills than Norwegian women, which in turn can affect hormone levels. ${ }^{40,41}$ Utah has one of the highest fertility rates in the USA, with 2 children for every one mother. ${ }^{42}$ In Norway, the fertility rate was 1.56 in 2018 and has remained stable under 2 in the study period. ${ }^{43}$ The percentage of pregnancies resulting from some form of fertility treatment is 4 in Utah and $6.6 \%$ in Norway. ${ }^{44,45}$ Exogenous hormones and endocrine disruptors have also been suggested as potential risk factors because of their capacity to perturb normal hormonal actions, However, there is a striking lack of human data to fill the current knowledge gaps. ${ }^{46,47}$

Several studies conducted among immigrant populations suggest an influence of life-style and environmental factors in the aetiology of TC cancer. ${ }^{48,49}$ Both, in Sweden and Denmark, firstgeneration immigrants from low-risk countries tend to have a lower risk of TC compared with native-born in these countries, whereas the risk in second-generation immigrants tends to be similar to that observed in native-born.

The interaction between environmental and genetic factors might play an important role in the risk of TC. ${ }^{50}$ Differences in genetic susceptibility might predispose some individuals to be more or less likely to develop a particular disease following exposure to an environmental factor. We observed a cessation of increase in incidence of TC among birth cohorts in the last 
period in both populations. The lack of further increase in the incidence rate might be explained by reaching the population fraction of susceptible males prone to acquire TC, given the interaction between their genetic susceptibility and environmental risk factors.

In our analysis we cannot distinguish between cohort effects and period effects that might influence different cohorts at different ages. By dividing the study population into age groups and investigating incidence rates within these groups we could perform a formal age-periodcohort analysis ${ }^{51}$ with the aim of understanding the relation between pure cohort effects and effects of certain time periods (maybe independent of age). This could potentially lead to improved understanding of the role of certain environmental exposures in the development of TC. However, due to a limited number of cases in many age groups, we have not pursued this strategy any further.

Previous studies have reported familial aggregation of TC in agreement with our findings, ${ }^{52}$ with higher risk for TC among brothers than sons in both Norway and Utah. Full brothers share $50 \%$ of their genes plus common environmental and gestational factors. However, no highly penetrant TC predisposition genes have been identified. ${ }^{6}$ An explanation of our finding may be sharing of intrauterine factors among brothers. For instance, levels of pregnancy estradiol, the main pregnancy oestrogen, have been found to be strongly associated in successive pregnancies of the same women. ${ }^{53}$ Black men have lower risk of TC. ${ }^{54}$ It has been hypothesized that as the black mothers have significantly higher testosterone levels, it may imply a lower risk to those children compared with children of white mothers. ${ }^{55}$ However, black or African Americans constitute less than $2 \%$ of the Utah population. ${ }^{56}$

Summarizing, the observed increase in TC incidence can be viewed as a consequence of a change in risk factors for TC in both Norway and Utah, probably environmental or lifestyle factors.

\subsection{Strengths and limitations}

A strength of this study is the availability of family information for a large number of individuals who emigrated from Scandinavia to Utah during the last 150 years. Second, both countries have detailed nationwide cancer registries. Utah's and Norway's cancer registries rank amongst the top regarding data quality and completeness..$^{23,24}$ This avoids ascertainment, referral, and recall bias. Third, there is a pronounced difference in the incidence of testicular 
cancer between Scandinavia and Utah. This allowed us to conduct a unique comparative study of familial aggregation of cancer. Incidence rates were calculated for individuals born between 1951 and1984, to allow the same risk window (until the age of 30) for each individual to develop TC. Thus, it allows truncation-free analyses within the same birth cohort from 1951 in Norway and from 1966 in Utah.

Some limitations are also noted. The incidence of TC peak at the ages 30-34 years, the study could be more generalizable with a longer follow up period including individuals older than 30 years. Cancer cases occurring before 1966 in Utah and 1953 in Norway are censored; therefore, our analysis was left-truncated starting at 1966 and 1953, respectively. In consequence the incidence rates in the first period might be some lower than the expected rates. Nevertheless, TC incidence peak after puberty and TC in children below the age of 15 is uncommon and comprises only $4 \%$ of childhood cancers. ${ }^{1}$ Another limitation was our inability to pool data for Norway and Utah, preventing direct testing of differences between the two populations. In Utah we used the last known date of residence to censure individuals; those without information on this and moving from Utah were censored to follow up. However, the percent change in the size of Utah population is less than $2 \%$ according to 2010 2016 estimates. ${ }^{57}$ The Utah data included only those individuals with genealogy data in the UPDB this may result in a potential for selection bias. However, approximately $84 \%$ of children born in Utah in 1950 had information on grandparents. ${ }^{58}$ The grade of completeness in later years might be higher due to link of UPDB with several registries and census. The study is based on individuals from two primarily Caucasian populations. It is unclear whether our results can be generalised to non-Caucasian populations. Utah has limited racial and ethnic diversity with non-Hispanic whites comprising nearly $80 \%$ of the population. Previous studies have shown that the UPDB population is genetically representative of US white and northern European populations. ${ }^{59,60}$ Ethnically, the residents of Norway are predominantly Caucasians. About $14 \%$ of the actual population in Norway are immigrants, whereby almost half of them come from other European countries. ${ }^{61}$

Although Norwegians, Swedes and Danes are quite homogeneous populations, it should be noted that the incidence of TC in Denmark and Norway is about twice the incidence rates in Sweden. ${ }^{30}$ This could introduce some bias in our study. If we made the comparison between the Utah population (and specifically the population with Scandinavian ancestry) and the 
Scandinavian population instead of the Norwegian population, the difference would have been somewhat smaller.

\section{Conclusion}

We found a clear difference in TC incidence among individuals born in Norway and descendants of Scandinavian people born in Utah. Incidence of TC showed a rapid increase both in Utah and in Norway with consecutive birth cohorts. The increase was highest in Norway. These differences in TC rates point to the possibility of environmental influences and/or lifestyle factors. Elevated HR of TC in first degree relatives indicates a heritable contribution. However, simultaneous familial exposure or shared familial susceptibility to an environmental factor may also lead to familial aggregation of TC.

\section{Acknowledgements}

This research was supported by the Utah Cancer Registry, which is funded by the National Cancer Institute's SEER Program, Contract No. HHSN261201800016I, the US Center for Disease Control and Prevention's National Program of Cancer Registries, Cooperative Agreement No. NU58DP0063200-01, with additional support from the University of Utah and Huntsman Cancer Foundation.

Partial support for all datasets within the Utah Population Database is provided by the University of Utah, Huntsman Cancer Institute and the Huntsman Cancer Institute Cancer Center Support grant, P30 CA42014 from the National Cancer Institute.

LACA acknowledges support from the Huntsman Cancer Foundation.

We also thank The Norwegian Cancer Registry as a data contributor. Certain data used in this publication were obtained from the Norwegian Cancer Registry. The authors assume full responsibility for analysis and interpretation of these data.

Conflict of Interest: The authors declare no conflict of interest.

Funding: This investigation was supported by a research grant 2016/FO76902 (Ruby Del Risco Kollerud) from ExtraStiftelsen through the Norwegian Cancer Society, the Research 
Council of Norway, the Wedel Jarlsbergs and Olav Raagholt og Gerd Meidel Raagholts Foundation.

\section{References}

${ }^{1}$ Kusler KA, Poynter JN. International testicular cancer incidence rates in children, adolescents and young adults. Cancer Epidemiol. 2018;56:106-111.

${ }^{2}$ Purdue MP, Devesa SS, Sigurdson AJ, McGlynn KA. International patterns and trends in testis cancer incidence. Int J Cancer. 2005;115:822-7.

${ }^{3}$ Jacobsen R, Møller H, Thoresen SØ, Pukkala E, Kjaer SK, Johansen C. Trends in testicular cancer incidence in the Nordic countries, focusing on the recent decrease in Denmark. Int J Androl. 2006;29:199-204.

${ }^{4}$ Møller H. Decreased testicular cancer risk in men born in wartime. J Natl Cancer Inst. 1989;81:1668-9.

${ }^{5}$ Keyes KM, Utz RL, Robinson W, Li G. What is a cohort effect? Comparison of three statistical methods for modeling cohort effects in obesity prevalence in the United States, 1971-2006. Soc Sci Med. 2010;70:1100-8.

${ }^{6}$ Del Risco Kollerud R, Ruud E, Haugnes HS, Cannon-Albright LA, Thoresen M, Nafstad P, Vlatkovic L, Blaasaas KG, Næss Ø, Claussen B. Family history of cancer and risk of paediatric and young adult's testicular cancer: A Norwegian cohort study. Br J Cancer. 2019;120:1007-1014.

${ }^{7}$ AlDubayan SH, Pyle LC, Gamulin M, Kulis T, Moore ND, Taylor-Weiner A, et al. Association of Inherited Pathogenic Variants in Checkpoint Kinase 2 (CHEK2) With Susceptibility to Testicular Germ Cell Tumors. JAMA Oncol. 2019 Jan 24. doi:

10.1001/jamaoncol.2018.6477.

${ }^{8}$ Crockford GP1, Linger R, Hockley S, et al. Genome-wide linkage screen for testicular germ cell tumour susceptibility loci. Hum Mol Genet. 2006;15:443-51.

${ }^{9}$ Wang Z, McGlynn KA, Rajpert-De Meyts E, Bishop DT, et al. Meta-analysis of five genome-wide association studies identifies multiple new loci associated with testicular germ cell tumor. Nat Genet. 2017;49:1141-1147.

${ }^{10}$ Litchfield K, Levy M, Orlando G, Loveday C, Law PJ, et al. Identification of 19 new risk loci and potential regulatory mechanisms influencing susceptibility to testicular germ cell tumor. Nat Genet. 2017;49:1133-1140.

${ }^{11}$ Xing JS, Bai ZM. Is testicular dysgenesis syndrome a genetic, endocrine, or environmental disease, or an unexplained reproductive disorder? Life Sci. 2018;194:120-129.

${ }^{12}$ Sharpe RM, Skakkebaek NE. Are oestrogens involved in falling sperm counts and disorders of the male reproductive tract? Lancet. 1993;341:1392-5.

${ }^{13}$ Skakkebaek NE, Rajpert-De Meyts E, Main KM. Testicular dysgenesis syndrome: an increasingly common developmental disorder with environmental aspects. Hum Reprod. 2001;16:972-8.

${ }^{14}$ Jenson A. History of the Scandinavian Mission Arno Press, 1927. University of Wisconsin.

${ }^{15}$ Statistics Norway. How big is the immigration to Norway - now, before and internationally? 2012. (In Norwegian) Accessed (03.2019).

${ }^{16}$ Kero R. From Sweden to America. Scandinavian Economic History Review, 2011;24: 167169.

${ }^{17}$ Hvidt K. Mass Emigration from Denmark to the United States 1868-1914American Studies in Scandinavia, 9 (1972). 
${ }^{18}$ West DW, Lyon JL, Gardner JW. Cancer risk factors: an analysis of Utah Mormons and non-Mormons. J Natl Cancer Inst. 1980;65:1083-95.

${ }^{19}$ Patton MQ. Enhancing the quality and credibility of qualitative analysis. Health Serv Res. 1999;34:1189-208.

${ }^{20}$ Huntsman Cancer Institute. Utah Population Database

https://uofuhealth.utah.edu/huntsman/utah-population-database/ (Accessed January, 2019.

${ }^{21}$ DuVall SL, Fraser AM, Rowe K, Thomas A, Mineau GP. Evaluation of record linkage between a large healthcare provider and the Utah Population Database. J Am Med Inform Assoc. 2012;19:e54-9.

${ }^{22}$ Larsen IK, Småstuen M, Johannesen TB, Langmark F, Parkin DM, Bray F, Møller B. Data quality at the Cancer Registry of Norway: an overview of comparability, completeness, validity and timeliness. Eur J Cancer 2009. 45;1218-1231.

${ }^{23}$ Huyghe E, Matsuda T, Thonneau P. Increasing incidence of testicular cancer worldwide: a review. J Urol. 2003;170:5-11.

${ }^{24}$ Levi F, Te VC, Randimbison L, La Vecchia C. Trends in testicular cancer incidence in Vaud, Switzerland. Eur J Cancer Prev. 2003;12:347-9.

${ }^{25}$ Jacobsen R, Møller H, Thoresen SØ, Pukkala E, Kjaer SK, Johansen C. Trends in testicular cancer incidence in the Nordic countries, focusing on the recent decrease in Denmark. Int J Androl. 2006;29:199-204.

${ }^{26}$ Weir HK, Marrett LD, Moravan V. Trends in the incidence of testicular germ cell cancer in Ontario by histologic subgroup, 1964-1996. CMAJ. 1999;160:201-5.

${ }^{27}$ Pharris-Ciurej ND, Cook LS, Weiss NS. Incidence of testicular cancer in the United States: has the epidemic begun to abate? Am J Epidemiol. 1999;150:45-6.

${ }^{28}$ McGlynn KA, Devesa SS, Sigurdson AJ, Brown LM, Tsao L, Tarone RE. Trends in the incidence of testicular germ cell tumors in the United States. Cancer. 2003;97:63-70.

${ }^{29}$ Toppari J, Kaleva M, Virtanen HE. Trends in the incidence of cryptorchidism and hypospadias, and methodological limitations of registry-based data. Hum Reprod Update. 2001;7:282-6.

${ }^{30}$ Schnack TH, Poulsen G, Myrup C, Wohlfahrt J, Melbye M. Familial coaggregation of cryptorchidism, hypospadias, and testicular germ cell cancer: a nationwide cohort study. J Natl Cancer Inst. 2010;102:187-92.

${ }^{31}$ Sharpe RM, Skakkebaek NE. Are oestrogens involved in falling sperm counts and disorders of the male reproductive tract? Lancet. 1993;341:1392-5.

32 Skakkebaek NE, Rajpert-De Meyts E, Main KM. Testicular dysgenesis syndrome: an increasingly common developmental disorder with environmental aspects. Hum Reprod. 2001;16:972-8.

${ }^{33}$ Sharpe RM. The 'oestrogen hypothesis'- where do we stand now? Int J Androl. 2003;26:215.

${ }^{34}$ Martin O, Shialis T, Lester J, Scrimshaw M, Boobis A, Voulvoulis N. Testicular dysgenesis syndrome and the estrogen hypothesis: a quantitative meta-analysis. Cien Saude Colet. 2008;13:1601-18.

${ }^{35}$ Dorgan JF, Judd JT, Longcope C, Brown C, Schatzkin A, Clevidence BA, et al. Effects of dietary fat and fiber on plasma and urine androgens and estrogens in men: a controlled feeding study. Am J Clin Nutr. 1996;64:850-5.

36 Tuomisto J1, Holl K, Rantakokko P, Koskela P, Hallmans G, Wadell G, et al. Maternal smoking during pregnancy and testicular cancer in the sons: a nested case-control study and a meta-analysis. Eur J Cancer. 2009;45:1640-8. 
${ }^{37}$ Mongraw-Chaffin ML, Cohn BA, Anglemyer AT, Cohen RD, Christianson RE. Maternal smoking, alcohol, and coffee use during pregnancy and son's risk of testicular cancer.

Alcohol. 2009;43:241-5.

${ }^{38}$ America's Health Rankings analysis of CDC, Behavioral Risk Factor Surveillance System, United Health Foundation, AmericasHealthRankings.org, Accessed August, 2019. Website: https://www.americashealthrankings.org/explore/annual/measure/Smoking/state/UT ${ }^{39}$ Statistics Norway. Tobacco, alcohol and other drugs. Accessed August, 2019. Website: https://www.ssb.no/en/royk

${ }^{40}$ West DW, Lyon JL, Gardner JW. Cancer risk factors: an analysis of Utah Mormons and non-Mormons. J Natl Cancer Inst. 1980;65:1083-95.

${ }^{41}$ Conley LJ. Childbearing and childrearing practices in Mormonism. Neonatal Netw. 1990;9:41-8.

${ }^{42}$ Mathews TJ, Brady E. Hamilton. Total Fertility Rates by State and Race and Hispanic Origin: United States, 2017. National Vital Statistics ReportsVolume. ReportsVolume 68, Number 1. January 10, 2019.

${ }^{43}$ Statistics Norway. Decline in fertility. Published: 12 March 2019. Accessed in August 2019.

https://www.ssb.no/en/befolkning/artikler-og-publikasjoner/decline-in-fertility--379997

${ }^{44}$ Michelle JK, Osterman MHS, Joyce A, et al. Newly Released Data From the Revised U.S. Birth Certificate, 2011. National Vital Statistics Reports. Volume 62, Number 4. December 10, 2013.

${ }^{45}$ Boivin J, Bunting L, Collins JA, Nygren KG. International estimates of infertility prevalence and treatment-seeking: potential need and demand for infertility medical care. Hum Reprod. 2007;22:1506-12.

${ }^{46}$ Le Moal J, Sharpe RM, Jorgensen N, Levine H, et al.Toward a multi-country monitoring system of reproductive health in the context of endocrine disrupting chemical exposure. Eur J Public Health. 2016;26:76-83.

${ }^{47}$ Giannandrea F, Paoli D, Figà-Talamanca I, Lombardo F, Lenzi A, Gandini L. Effect of endogenous and exogenous hormones on testicular cancer: the epidemiological evidence. Int $\mathrm{J}$ Dev Biol. 2013;57:255-63.

${ }^{48}$ Beiki O, Granath F, Allebeck P, Akre O, Moradi T. Subtype-specific risk of testicular tumors among immigrants and their descendants in Sweden, 1960 to 2007. Cancer Epidemiol Biomarkers Prev. 2010;19:1053-65.

${ }^{49}$ Myrup C, Westergaard T, Schnack T, Oudin A, Ritz C, Wohlfahrt J, Melbye M. Testicular cancer risk in first- and second-generation immigrants to Denmark. J Natl Cancer Inst. 2008;100:41-7.

${ }^{50}$ Chris Wild Paolo Vineis Seymour Garte. Book Editors. Molecular Epidemiology of Chronic Diseases. Chapter 5: Individual Susceptibility and Gene-Environment Interaction. Print ISBN:9780470027431 2008 John Wiley \& Sons, Ltd.

${ }^{51}$ Holford TR. The estimation of age, period and cohort effects for vital rates. Biometrics. 1983;39:311-24.

${ }^{52}$ Rajpert-De Meyts E, McGlynn KA, Okamoto K, Jewett MA, Bokemeyer C. Testicular germ cell tumours. Lancet. 2016;387:1762-74.

${ }_{53}$ Bernstein L, Lipworth L, Ross RK, Trichopoulos D. Correlation of estrogen levels between successive pregnancies. Am J Epidemiol. 1995;142:625-8.

${ }^{54}$ Gajendran VK, Nguyen M, Ellison LM. Testicular cancer patterns in African-American men. Urology. 2005;66:602-5. 
55 Zhang Y, Graubard BI, Longnecker MP, Stanczyk FZ, Klebanoff MA, McGlynn KA. Maternal hormone levels and perinatal characteristics: implications for testicular cancer. Ann Epidemiol. 2007; 17:85-92.

${ }^{56}$ United States Census Bureau. Population estimates. Website, https://www.census.gov/quickfacts/fact/table/webercountyutah\# (Accesses August, 2019). ${ }^{57}$ Emily Harris, M.S. State and County Population Estimates for Utah: 2016. Kem C. Gardner Policy Institute. December 2016. Website accessed august 2019:

https://gardner.utah.edu/wp-content/uploads/20161207_2016-DUPC-Estimates-SummaryFinal.pdf

${ }^{58}$ Huntsman cancer institute, University of Utah and University of Utah Health. The Utah Population Database. Overview. Accessed December 2019. Website: https:/uofuhealth.utah.edu/huntsman/utah-population-database/data/ ${ }^{59}$ Office of Health Disparities (2015). Health Status by Race and Ethnicity 2015.

Salt Lake City, UT: Utah Department of Health.

${ }^{60}$ Jorde LB. Inbreeding in the Utah Mormons: an evaluation of estimates based on pedigrees, isonymy, and migration matrices. Ann Hum Genet. 1989;53:339-55.

${ }^{61}$ Statistisk Norway. 14 per cent of the population are immigrants (In Norwegian), Accessed January 2019. https://www.ssb.no/befolkning/artikler-og-publikasjoner/14-prosent-avbefolkningen-er-innvandrere 
Table 1

Table 1. Characteristics of males born in Norway and Utah in the period 1951 to 2015. Cases are men who were diagnosed with testicular cancer before age 30 years in Utah (1966-2015) and in Norway (1953-2015).

\begin{tabular}{|l|c|c|c|c|}
\hline & \multicolumn{2}{|c|}{ Cases } & \multicolumn{2}{c|}{ Non-cases } \\
\hline & Number & $\%$ & Number & $\%$ \\
\hline Children born in Utah & & & & \\
\hline Country of origin of ancestors & & 0.1 & 832,305 & 99.9 \\
\hline Not Scandinavia & 186 & 35 & 262,739 & 31.6 \\
\hline Scandinavia & 345 & 65 & 569,566 & 68.4 \\
\hline Tumour histology & & & & \\
\hline Seminoma & 153 & 28.8 & & \\
\hline Non-seminoma & 349 & 65.7 & & \\
\hline Unclassified & 29 & 5.5 & & \\
\hline Mean age at cancer diagnosis (SD) & & & & \\
\hline All cases & $22(6.0)$ & & & \\
\hline Seminoma & $25(2.5)$ & & & \\
\hline Non-seminoma & $21(6.3)$ & & & \\
\hline Children born in Norway & & & & \\
\hline Tumour histology & 2,686 & 0.1 & $1,971,601$ & \\
\hline Seminoma & & & & \\
\hline Non-seminoma & 761 & 28.3 & & \\
\hline Unclassified & 1654 & 61.6 & & \\
\hline Mean age at cancer diagnosis (SD) & 271 & 10.1 & & \\
\hline All cases & $24(4.9)$ & & & \\
\hline Seminoma & $26(3.1)$ & & & \\
\hline Non-seminoma & $23(5.2)$ & & & \\
\hline Abbrations: SD, standard & & & \\
\hline
\end{tabular}

Abbreviations: SD, standard deviation

Table 2

Table 2. Risk of testicular cancer according to family history of testicular cancer among a cohort of males born in Norway and Utah in the period 1951-2015 and who were diagnosed with testicular cancer before age 30 years in Utah (1966-2015) and in Norway (1953-2015). Adjusted hazard ratios (HR) with 95\% confidence interval (CI) are presented separately for the whole population in Utah and for Norway.

\begin{tabular}{|l|c|c|c|c|l|l|}
\hline & All children born in Utah & & \multicolumn{2}{|l|}{ All children born in Norway } & \\
\hline Family history of testicular cancer & Cases & HR $(\mathbf{9 5 \%}$ CI) & p-value & Cases & HR (95\% CI) & p-value \\
\hline & & & & & & \\
& & & & & & \\
\hline Father & 4 & $\mathbf{3 . 4 7}(\mathbf{1 . 3 0 - 9 . 2 8})$ & 0.0132 & 35 & $\mathbf{4 . 4 1 ( 3 . 1 6 - 6 . 1 6 )}$ & $<\mathbf{0 . 0 0 0 1 *}$ \\
\hline Brothers & 23 & $\mathbf{9 . 8 7}(\mathbf{5 . 6 8 - 1 7 . 1 6})$ & $<\mathbf{0 . 0 0 0 1 *}$ & 76 & $\mathbf{6 . 0 2}(\mathbf{4 . 8 0 - 7 . 5 5 )}$ & $<\mathbf{0 . 0 0 0 1 *}$ \\
\hline All first-degree relatives & 25 & $\mathbf{6 . 7 4}(\mathbf{4 . 2 7 - 1 0 . 6 1 )}$ & $<\mathbf{0 . 0 0 0 1 *}$ & 116 & $\mathbf{5 . 5 4}(\mathbf{4 . 6 0 - 6 . 6 8 )}$ & $<\mathbf{0 . 0 0 0 1 *}$ \\
\hline
\end{tabular}

The model was adjusted for number of relatives according to type analysis.

Cases: number of cancer cases with relatives affected.

NC: not calculated

Bolding of HRs shows that $95 \%$ CI does not include 1.00 .

$*$ P-values $<\sim 0,0004$ after Bonferroni test correction are still significant and highlighted in the Table. 


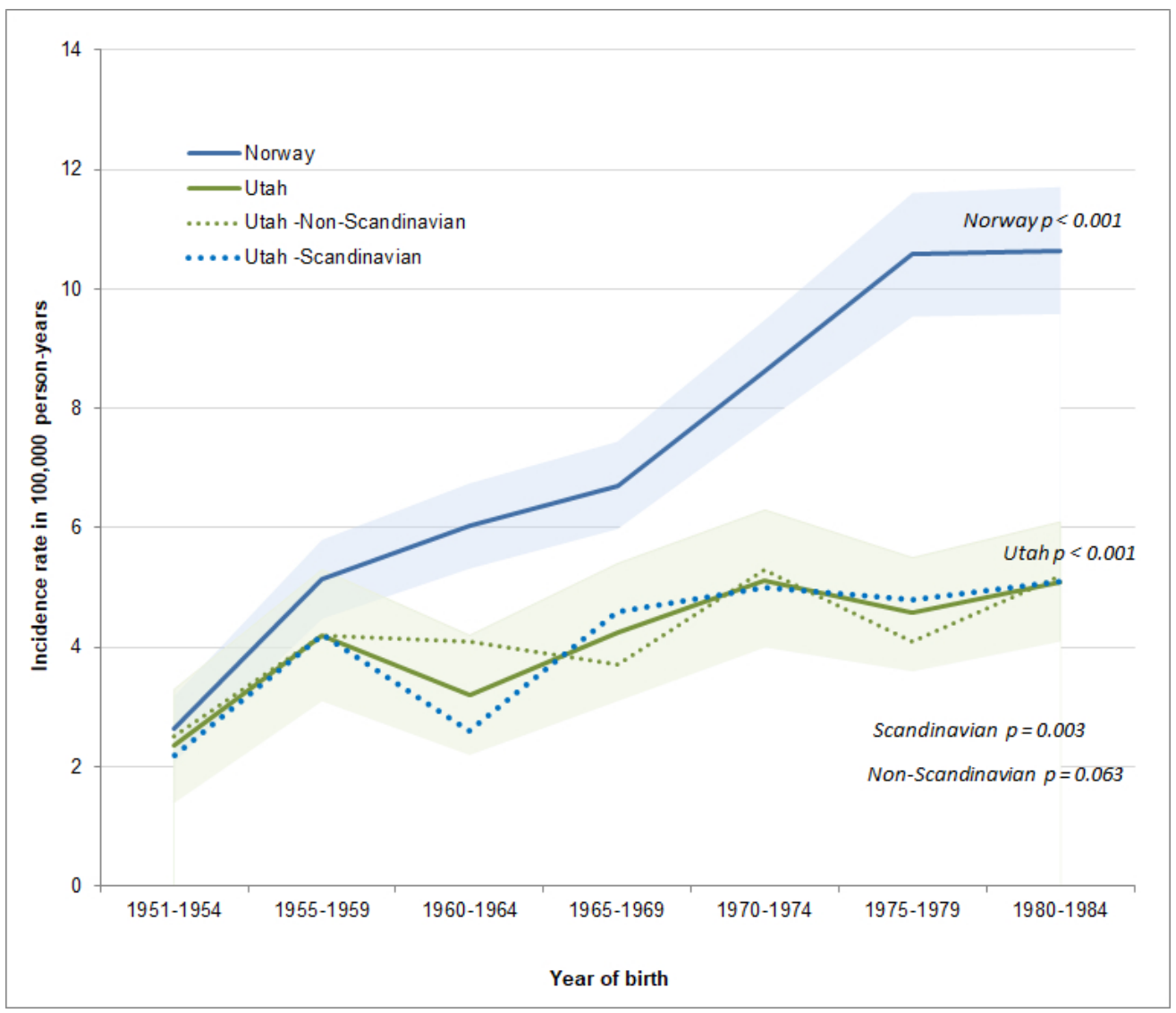

Figure 1. Testicular cancer incidence rates with 95\% confidence intervals among males born in Norway and Utah in the period 1951-2015 and who were diagnosed before 30 years with TC in Utah (1966-2015) and in Norway (1953-2015).

In Utah the incidence rates are presented separated with dotted lines for males with and without Scandinavian ancestors. Light blue and green colour represents $95 \%$ confidence intervals. $\mathrm{P}$ means $\mathrm{p}$ values for trend.

\section{$202 \times 173 \mathrm{~mm}(96 \times 96$ DPI $)$}




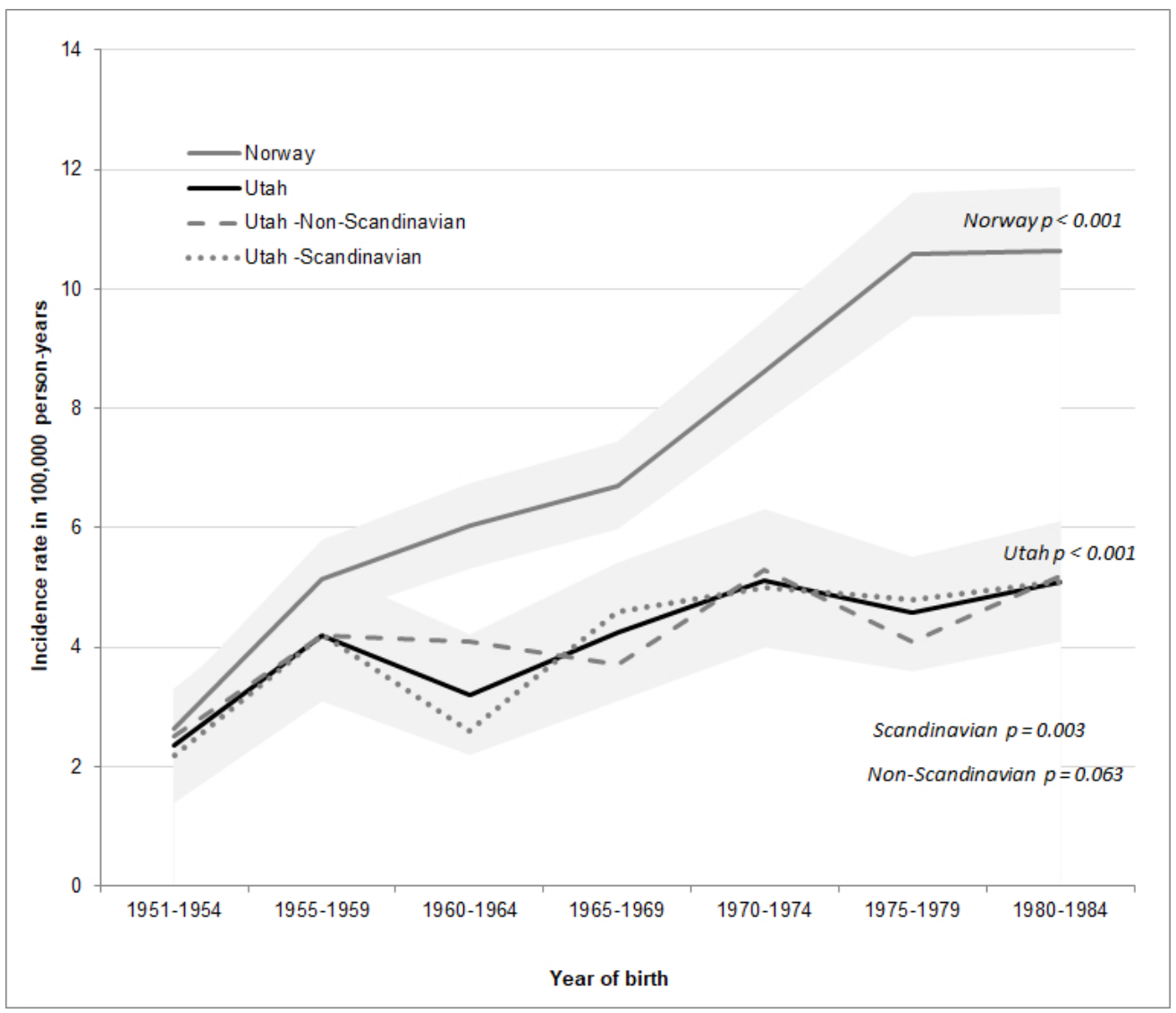

Figure 1. Testicular cancer incidence rates with 95\% confidence intervals among males born in Norway and Utah in the period 1951-2015 and who were diagnosed before 30 years with TC in Utah (1966-2015) and in Norway (1953-2015).

In Utah the incidence rates are presented separated with dotted lines for males with and without Scandinavian ancestors. Light grey colour represents $95 \%$ confidence intervals. $\mathrm{P}$ means $\mathrm{p}$ values for trend. 


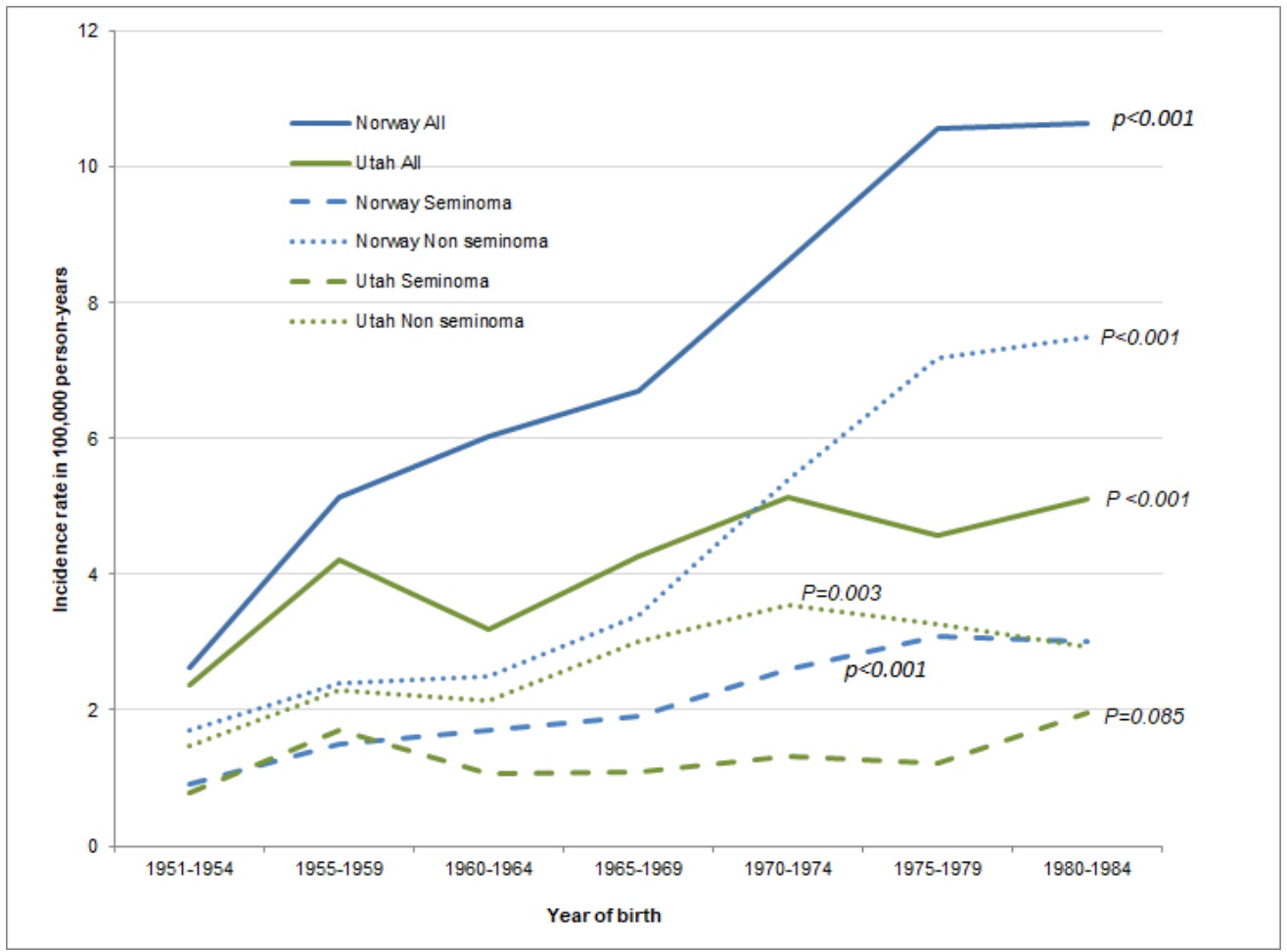

Figure 2. Testicular cancer incidence rates across histological groups among males born in Norway and Utah in the period 1951 to 2015 and who were diagnosed before 30 years with TC in Utah (1966-2015) and in Norway (1953-2015).

$P$ means $\mathrm{p}$ values for trend.

$193 \times 143 \mathrm{~mm}(96 \times 96 \mathrm{DPI})$ 


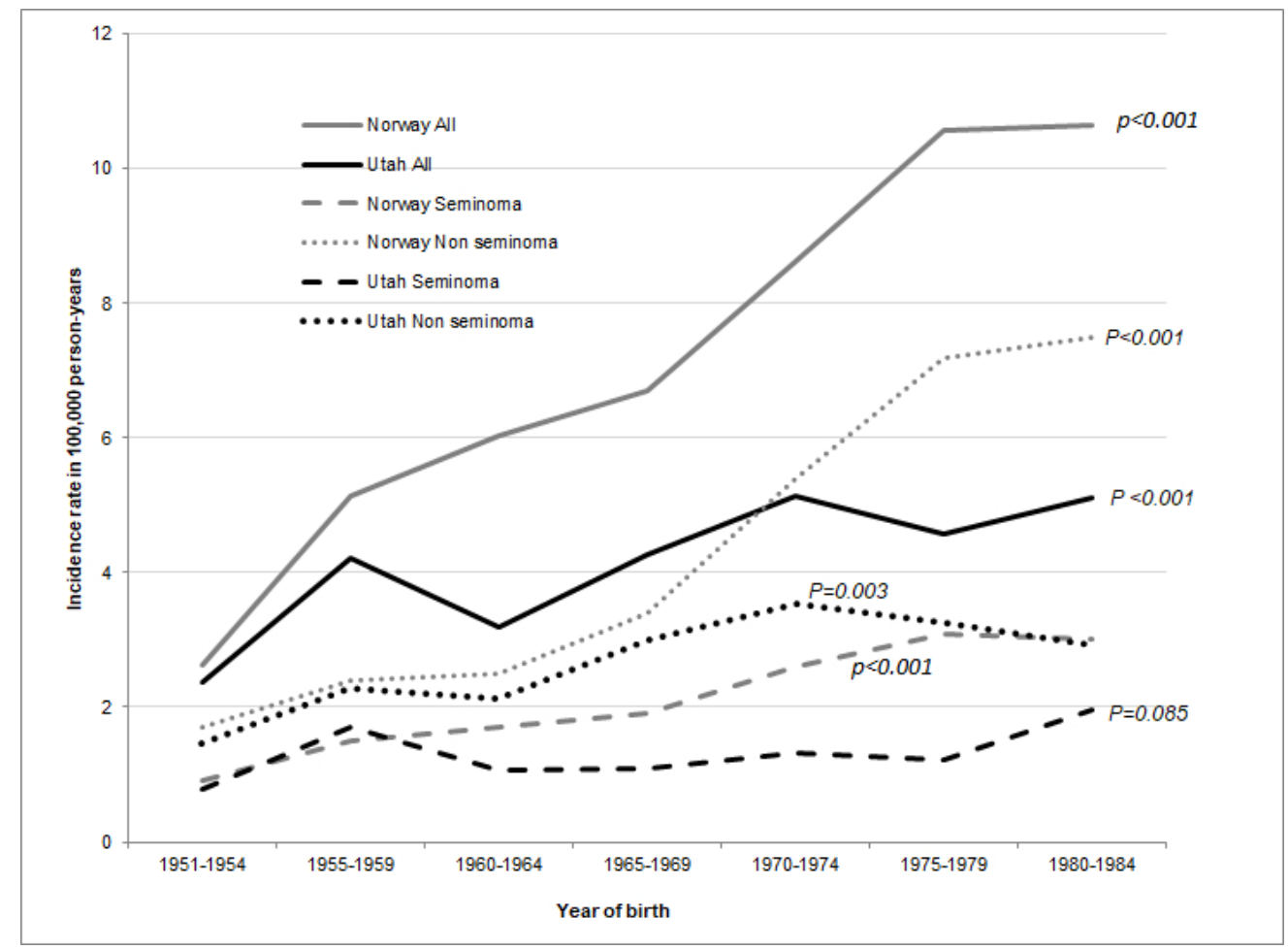

Figure 2. Testicular cancer incidence rates across histological groups among males born in Norway and Utah in the period 1951 to 2015 and who were diagnosed before 30 years with TC in Utah (1966-2015) and in Norway (1953-2015).

$P$ means $p$ values for trend.

$193 \times 143 \mathrm{~mm}(96 \times 96 \mathrm{DPI})$ 